\title{
Blood Purification Device Using Membranes Derived from Poly(vinyl alcohol), and Copolymer of Ethylene and Vinyl Alcohol
}

\author{
Dedicated to the Memory of the late Professor Ichiro Sakurada
}

Yutaka SAKURADA, Akinori SUEOKA, and Masaru KAWAHASHI

Medical Products Division, Kuraray Co., Ltd., 1-12-39 Umeda, Kita-ku, Osaka 530, Japan

(Received January 23, 1987)

\begin{abstract}
Hollow fiber membranes have been developed by using poly(vinyl alcohol) (PVA) and ethylene-vinyl alcohol copolymer (EVAL) for blood purification devices including hemodialyzer and plasmapheresis. This paper covers the manufacturing processes of those hollow fiber membranes, blood filtering characteristics of those membranes, and their application to blood purification devices. Hemodialyzer consisting of EVAL hollow fiber membrane enables us to conduct nonanticoagulant hemodialysis because of excellent blood compatibility of the membrane, and exhibits improved efficacy for renal failure patients under hemodialysis because of unique permeation characteristics of the membrane. Double filtration plasmapheresis can be performed using two filters, plasma separator consisting of PVA hollow fiber membrane, and plasma fractionator consisting of EVAL hollow fiber membrane.

KEY WORDS Poly(vinyl alcohol) / Ethylene-Vinyl Alcohol Copolymer / Hollow Fiber Membrane / Manufacturing Process of Membrane / Microstructure of Membrane / Blood Purification / Hemodialysis / Plasmapheresis / Blood Compatibility / Blood Filtering Characteristics /
\end{abstract}

Poly(vinyl alcohol) (PVA) is a synthetic polymer discovered by W. C. Herrmann in 1924. The production volume of this unique polymer material has increased with a successful introduction of synthetic fiber Vinylon, ${ }^{1}$ which has been developed by Japanese scientists including I. Sakurada and commercialized in Japan in 1948.

The application of PVA to the medical field dates back to the 1950's when the formalized PVA sponge (product name: Ivalon) was used as the artificial skin or the filling material for the artificial blood vessel, artificial trachea, chest and subcutaneous tissue. ${ }^{2}$

Since then, various polymers such as silicone and poly(hydroxyethyl methacrylate) (polyHEMA) have been developed as biomedical materials for specific purposes, and thus the use of PVA as a biomedical material has become less frequent. Recently, considering the fact that the hydrogel composed of hydrophilic polymer such as poly-HEMA exhibits good blood compatibility, PVA and its copolymers have begun to draw attention again as typical hydrophilic polymer for medical application. By utilizing the technique developed and established in connection with fiber (Vinylon) production of PVA for many years, we have developed hollow fiber membranes derived from PVA and ethylene-vinyl alcohol copolymer (EVAL) which show excellent membrane characteristics for use in various kinds of blood purification devices, including hemodialyzer. For example, the hollow fiber membranes of EVAL and of PVA have been successfully employed for hemo- 
dialysis and plasma separation.

The purpose of this paper is to outline the manufacturing process of PVA and EVAL hollow fiber membranes, their blood filtration properties and applications to blood purification devices. Those are the results which we have established and found through years of research and development work.

\section{MANUFACTURING PROCESS AND STRUCTURE OF HOLLOW FIBER MEMBRANES DERIVED FROM PVA AND EVAL}

\section{PVA Hollow Fiber Membrane}

The PVA hollow fiber membrane comes in two types: industrial-use membrane with a homogeneous dense structure and medical-use membrane with a microporous structure.

The microporous PVA membrane is obtained by: dissolving PVA and poly(alkylene glycol) (PAG) in water to make a spinning solution under proper conditions; spinning it into a mixed coagulation bath of $\mathrm{NaOH}$ and $\mathrm{Na}_{2} \mathrm{SO}_{4}$ through the ring nozzles; and giving hollow fiber spun a water resisting property with acetal. ${ }^{3}$ When the membrane coagulates, there occurs phase separation between PVA and PAG. PAG which forms island is extracted, forming a microporous structure (Figure 1). As shown in Figure 2, the composition of the spinning solution at area 2 produces a homogeneous dense membrane, while the composition at area 3 produces a microporous membrane.

The pore size of a membrane can be controlled with the coagulation conditions in addition to the molecular weight and loading quantity of PAG. At present, several types of membrane with different pore sizes are available. Figure 3 shows the relationship between rejection rate of the particle of latex colloidal silica and size of particle for PVA hollow fiber membranes. ${ }^{4}$ The PVA-M membrane with small pore size (average pore size, $160 \AA$ ) is used for ascites filtration, while the PVA-S
A. Inner surface of hollow fiber

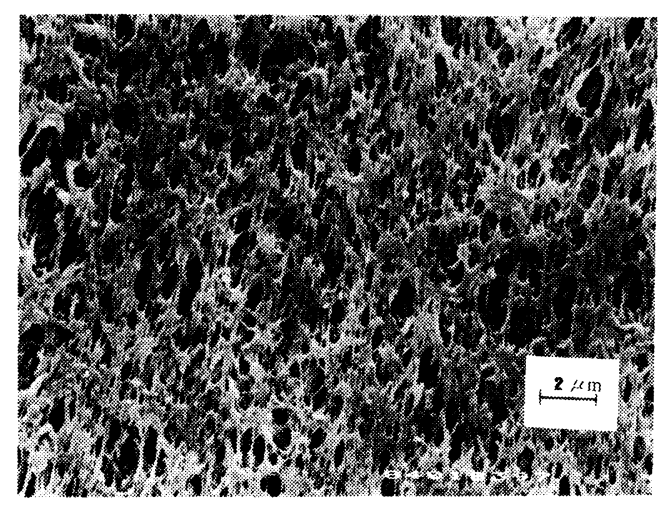

B. Cross sectional view of hollow fiber

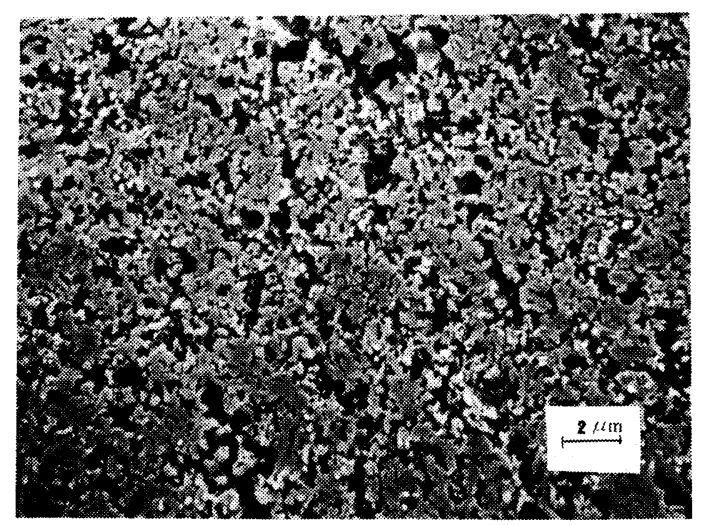

Figure 1. Electron micrographs of PVA hollow fiber membrane.

with large pore size (average pore size, $870 \AA$ ) is used for plasma separation.

Such medical-use PVA hollow fiber membranes have a crosslinked structure, maintaining hydrophilic properties and is stable at boiling temperature of water. Steam sterilization can be employed for these membranes. Because of their hydrophilicity, the membrane structure is reversible for the change from dry to wet condition or vice versa. This eliminates the need for such additives as glycerin or other type of surface-active agent which is used for giving the hydrophobic membranes hydrophilicity which is necessary for blood contact. This is one of the most important characteristics required for medical-use membranes from 
the viewpoint of safety.

\section{EVAL Hollow Fiber Membrane}

EVAL, one of the modified PVAs, is a random copolymer carrying hydrophilic (vinyl alcohol) and hydrophobic (ethylene) segments in a single molecule. EVAL is a unique polymer insoluble in water and exhibits good wet

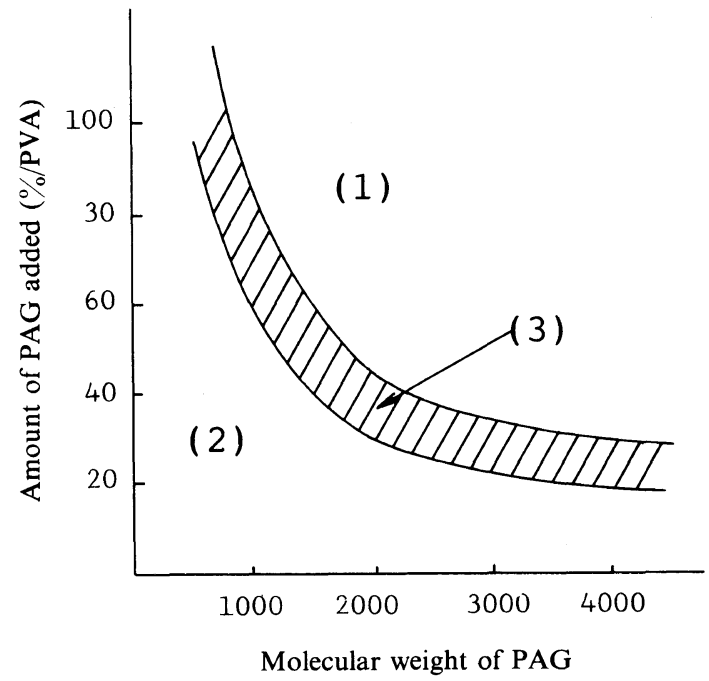

Figure 2. Relationship between composition of spinning solution and membrane structure. (1) heterogeneously dissolved spinning solution; (2) homogeneous dense-structured membrane; (3) microporous membrane. strength with hydrophilicity. The EVAL hollow fiber membrane is manufactured by: first dissolving EVAL in dimethyl sulfoxide (DMSO) to make spinning solution; spinning it into an aqueous coagulation bath through the ring nozzles; drawing and drying hollow fiber spun (Figure 4). ${ }^{5}$ The membrane properties are closely associated with the ratio of composition of hydrophilic groups to hydrophobic groups of EVAL. After an extensive research on the sieving coefficients for solutes, blood compatibility, mechanical strength and storage stability, EVAL whose ethylene content is about $30 \mathrm{~mol}^{\circ} \%$ is now used for medical applications.

Various types of membranes ranging from the dense structure to the microporous one can be produced by changing the spinning conditions. Especially, the pore size of membranes is controllable by adjusting the concentration of spinning solution and the temperature of coagulation bath. Figure 5 shows the protein rejection curves of EVAL hollow fiber membranes. Both EVAL-D and EVAL-C membranes which allow permeation of solutes having somewhat higher molecular weights than EVAL-D are used for hemodialysis. On the other hand, EVAL-2A, $-3 \mathrm{~A}$, and $-4 \mathrm{~A}$ membranes which fractionate proteins according to

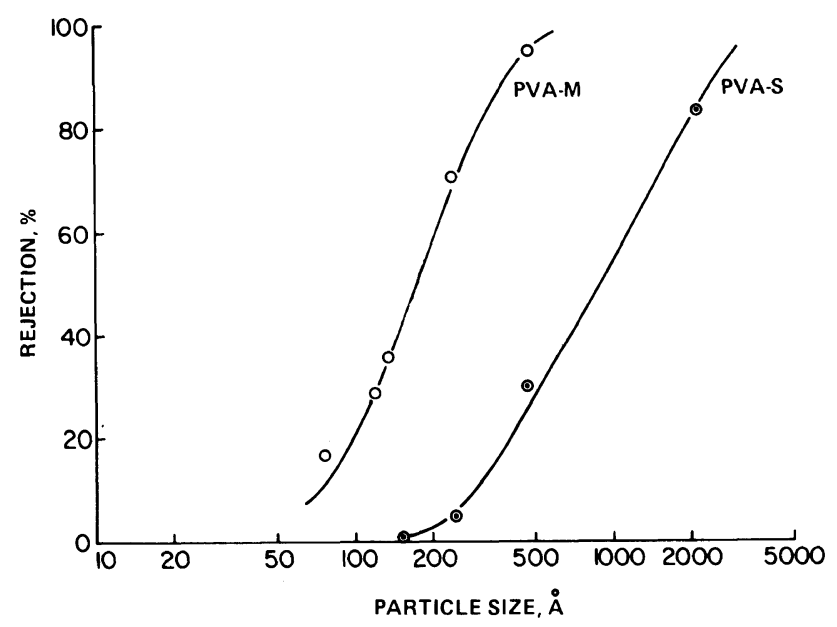

Figure 3. Rejection versus particle size for PVA hollow fiber membrane. 


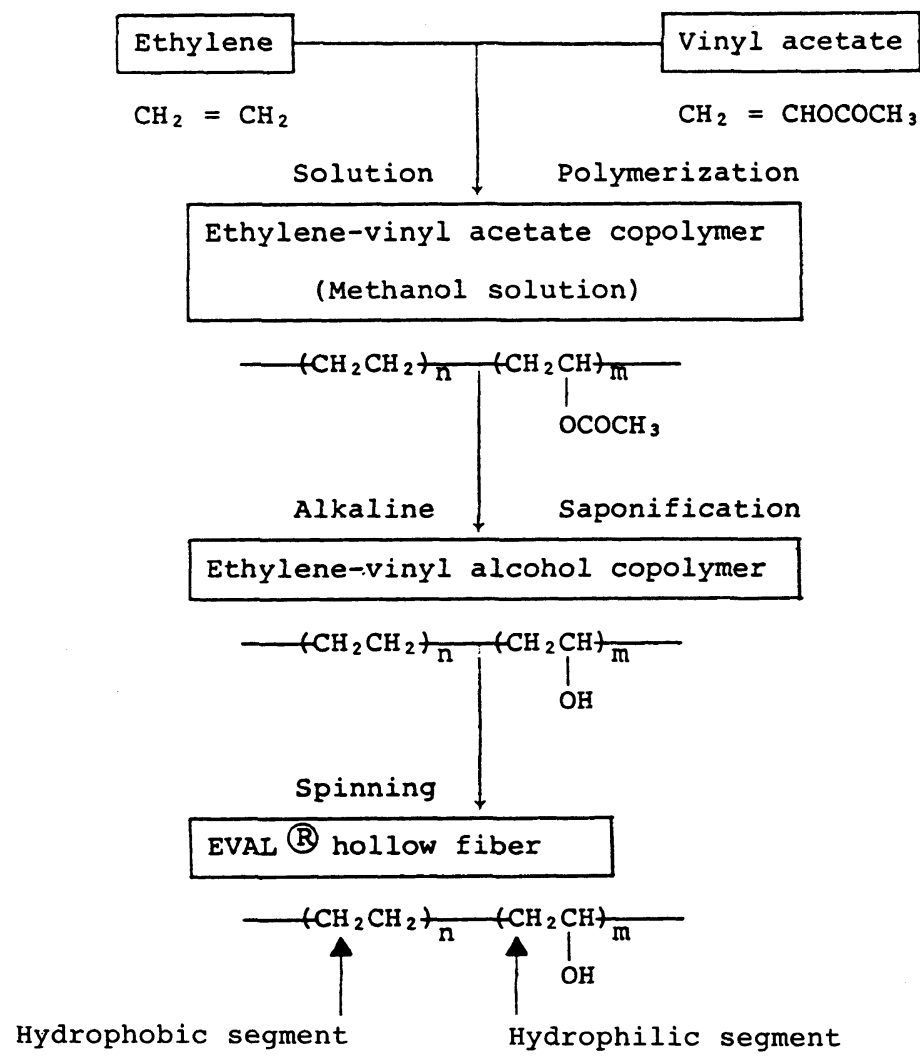

Figure 4. Schematic diagram of manufacturing process of EVAL hollow fiber membrane. ${ }^{5}$

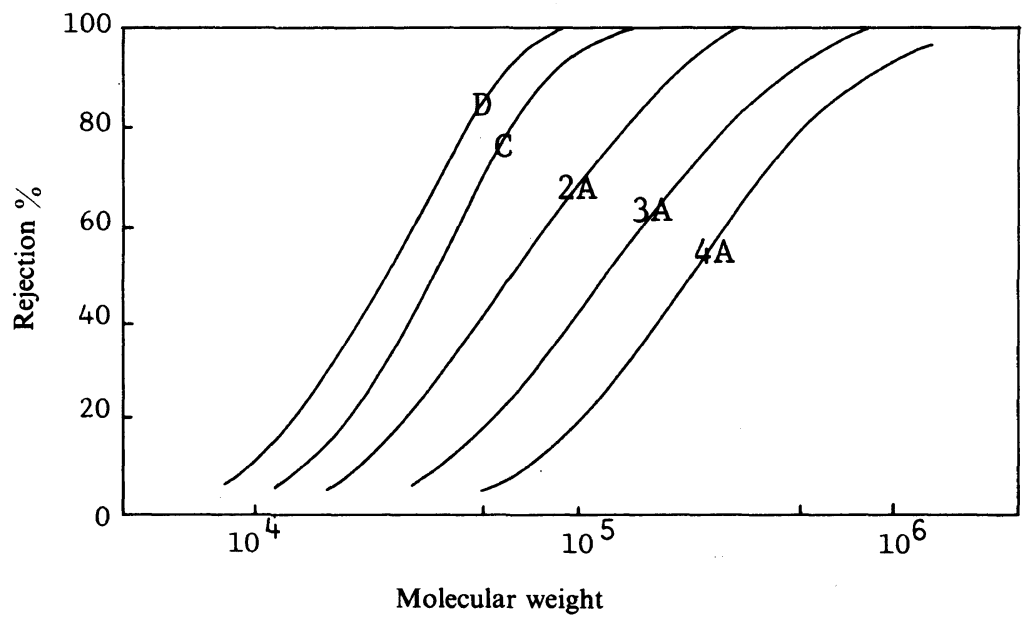

Figure 5. Rejection versus molecular weight for EVAL hollow fiber membrane. 
IA. Inner surface

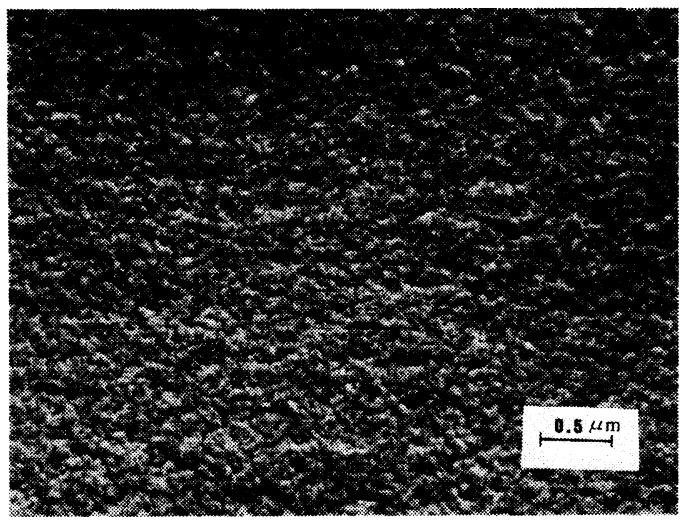

IIA. Inner surface

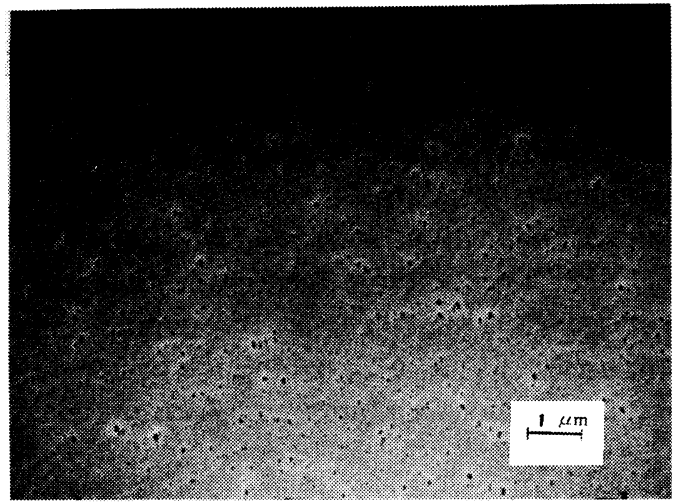

IB. Cross sectional view

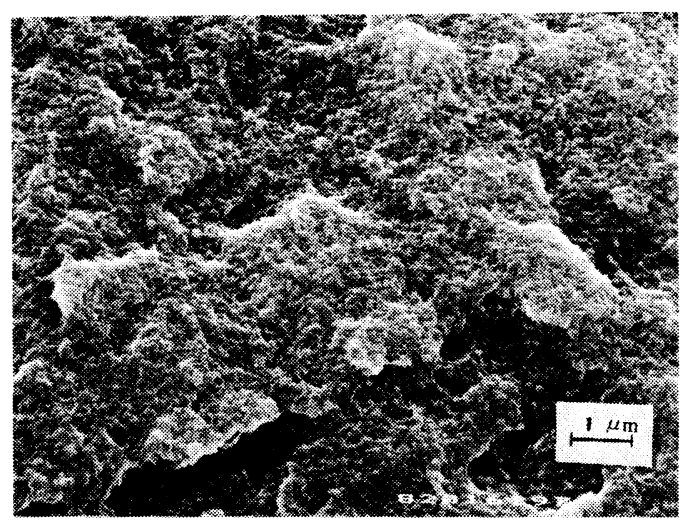

IIB. Cross sectional view

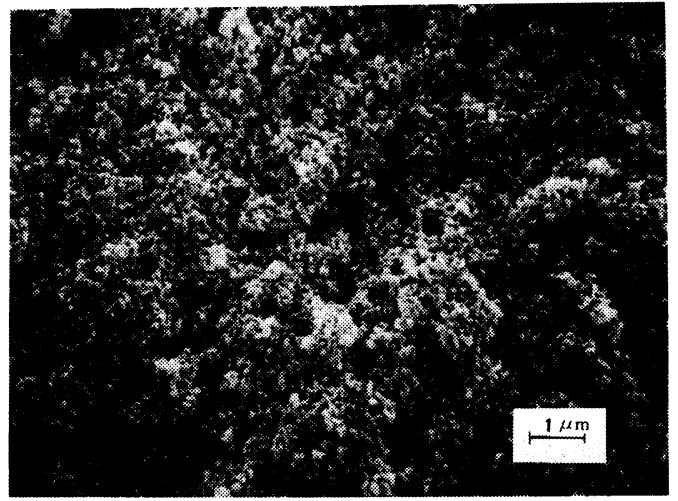

Figure 6. Electron micrographs of EVAL hollow fiber membrane. (I) EVAL-D; (II) EVAL-4A.

their molecular weights are used as plasma fractionators in plasmapheresis. Figure 6 shows the inner surfaces and cross sectional views of EVAL-D(I) and -4A(II). As seen in the photographs, EVAL-D membrane has a homogeneous dense structure, while EVAL4A membrane a microporous structure.

EVAL membranes which do not incorporate any plasticizer such as glycerin are at present sterilized by either ethylene oxide gas (EOG) or gamma-ray irradiation. EVAL hollow fiber membrane shows far less residual EOG after EOG sterilization than cellulosic membranes, probably because of the absence of plasticizer. These are also important characteristics of EVAL membrane in safety.

\section{APPLICATION OF HOLLOW FIBER MEMBRANES DERIVED FROM PVA AND EVAL TO VARIOUS KINDS OF BLOOD PURIFICATION}

\section{Blood Purification Device}

Presently available devices of artificial kidney and artificial liver can be classified as blood purification devices. Those and plasmapheresis have become widely used as a therapeutic modality for renal insufficiency and many intractable diseases, and occupy an important position in the medicalfield at present.

Blood purification device is a method which removes toxic substances from extracor- 

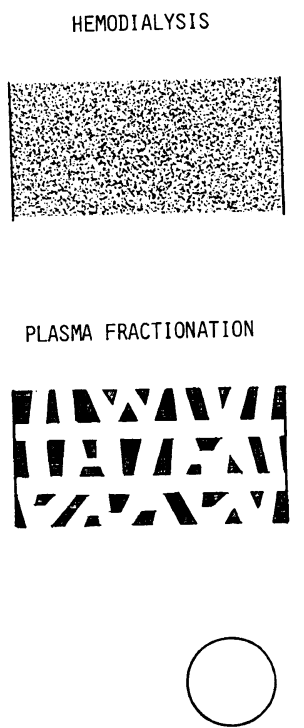

BLOOD CELI

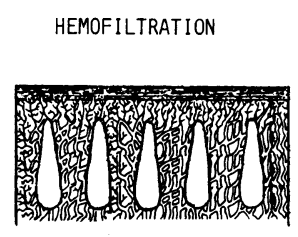

PLASMA SEPARATION
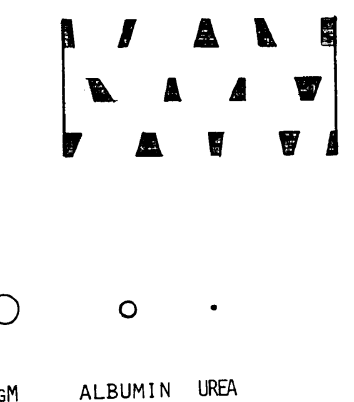

Figure 7. Structures of four types of membrane. ${ }^{6}$

poreally withdrawn blood by using the filter or adsorbent, and is used for the treatment of diseases that have toxic substances in the blood or allow the accumulation of harmful substances in the blood due to an impaired organic function. Recent development of the membrane manufacturing technology enabled us to widen the application of membrane to numbers of new blood purification devices. They include hemodialysis (HD), hemofiltration (HF), plasma separation (PS), and plasma fractionation (PF), each of which uses different kind of membrane.

Figure 7 shows schematical cross sectional views of four types of membrane available in the market. ${ }^{6}$ The PS (plasma separation) membrane has a microporous structure with submicron pores (Figure 1) and does not give any permeation of cell components, allowing the permeation of high molecular weight solutes such as IgM (molecular weight: approximately $950,000)$ nearly completely. Like the PS membrane, the PF (plasma fractionation) membrane also has a microporous structure (Figure $6 \mathrm{II})$, but its pore size is smaller so that proteins

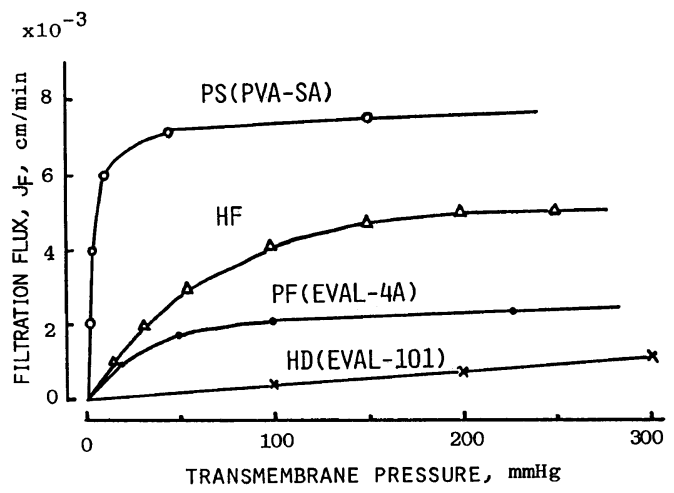

Figure 8. Relationship between filtration flux $\left(J_{\mathrm{F}}\right)$ and transmembrane pressure $\left(P_{\mathrm{TM}}\right)$ for four types of membrane (in vitro test with bovine blood).

in the plasma are selectively removed and permeated depending on their size. Both the HF (hemofiltration) membrane that has an asymmetric structure consisting of an inner thin skin and a finger-like supporting layer and the HD (hemodialysis) membrane that has a homogeneous skin layer on the whole membrane area (Figure 6I) prohibit the permeation of proteins such as albumin (molecular weight, 67,000).

At present, EVAL hollow fiber membranes are used for HD and PF, and PVA hollow fiber membranes for PS. We will describe the blood filtering characteristics of the hollow fiber membranes derived from PVA and EVAL and their applications to the artificial kidney and plasmapheresis in the following paragraphs.

\section{Blood Filtering Characteristics of Hollow Fiber} Membranes Derived from PVA and EVAL

Figure 8 shows the relationship between the transmembrane pressure $\left(P_{\mathrm{TM}}\right)$ and filtration flux $\left(J_{\mathrm{F}}\right)$ for HD membrane (EVAL-D), HF membrane (other synthetic polymer membrane produced by us), PF membrane (EVAL4A) and PS membrane (PVA-S), under the same filtration conditions (bovine blood: Hct, $39 \%$; TP, $6 \mathrm{~g} \mathrm{dl}^{-1}$; shear rate, $\left.190 \mathrm{~s}^{-1}\right){ }^{6}$ For HD membrane, $J_{\mathrm{F}}$ increases linearly as $P_{\mathrm{TM}}$ 


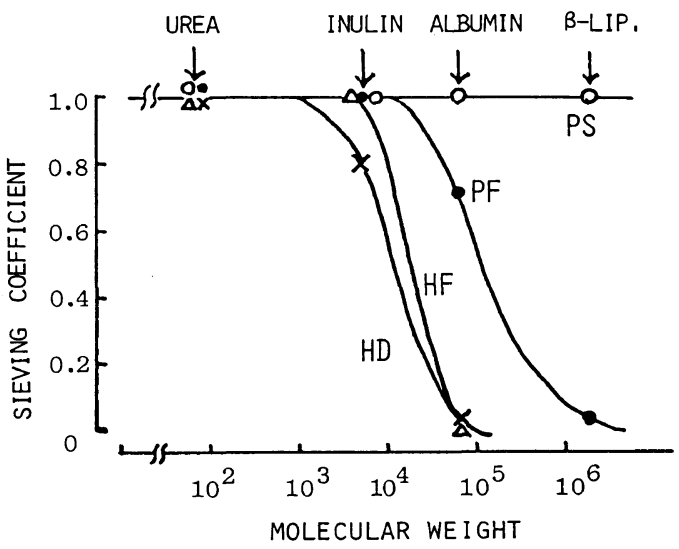

Figure 9. Sieving coefficients (SCs) of four types of membrane for solutes (in vitro test with bovine blood).

rises. For other membranes, although $J_{\mathrm{F}}$ increases linearly in the low $P_{\mathrm{TM}}$ region, it levels off thereafter and does not increase even if $P_{\mathrm{TM}}$ rises further. Since too high $P_{\mathrm{TM}}$ could cause unfavorable effects on blood cells (hemolysis) and result in a clogged membrane, it is necessary to adjust $P_{\mathrm{TM}}$ properly according to the type of the membrane. In the case of PS membrane, it should be operated under the $P_{\mathrm{TM}}$ less than $50 \mathrm{mmHg}$.

Figure 9 shows the sieving coefficients of different types of membrane for solutes of different molecular weights. ${ }^{6}$ The PS membrane whose pore size is greater than that of other types of membrane allows permeation of all the solutes. The HD membrane completely prohibits the permeation of albumin. Permeation characteristics of the PF membrane is just intermediate between those of the $\mathrm{HD}$ and PS membrane.

In order to design blood purification devices, it is essential to choose a type of membrane suitable to each purpose and to employ filtration conditions appropriate to the type of the membrane.

\section{Application to Artificial Kidney}

The development of the artificial kidney has made remarkable progress in recent years and more than 70,000 patients with chronic renal insufficiency are now treated annually with the artificial kidney in Japan; the number of treatments amounts to more than 10 million per annum. Hemodialysis (HD), which occupies most of the treatments by the artificial kidney, removes toxic substances in the blood such as urea and creatinine through diffusion by allowing blood in contact with dialysate across the dialyzing membrane.

The development of EVAL dialyzing membranes has been undertaken for the following reasons: (1) EVAL is hydrophilic but insoluble in water; (2) it is possible to design a membrane whose functions of permeability and mechanical strength are alloted properly by balancing the hydrophilicity and hydrophobicity; (3) it is possible to expect different characteristics of blood compatibility by endowing with the heterogeneous microstructure on the surface in addition to the chemical structure; (4) its safety is confirmed as material such as for the food package film.

Characteristics and Clinical Efficacy of the EVAL Hemodialyzer. The EVAL hemodialyzer consists of hollow fiber membranes with an inside diameter of $200 \mu \mathrm{m}$ and membrane thickness of $30 \mu \mathrm{m}$, and are available in several types with different membrane surface areas ranging from 0.8 to $2.0 \mathrm{~m}^{2}$. Figure 10 shows the permeability of the EVAL hemodialyzer for solutes. ${ }^{7}$ In comparison with cellulosic membrane, the permeability of the EVAL membrane is relatively lower for substances in the low molecular weight range but higher for substances in the middle and high molecular weight ranges. The pore size of the EVAL membrane ranges from 40 to $50 \AA$, larger than that of the cellulosic membrane and correlates well with its good permeability for substances in the middle and high molecular weight ranges. The permeability of the EVAL membrane is well recognized as a practical clinical merit.

The disequilibrium syndromes such as headache, nausea, and neuropathy are sometimes experienced by patients during dialysis. If the 


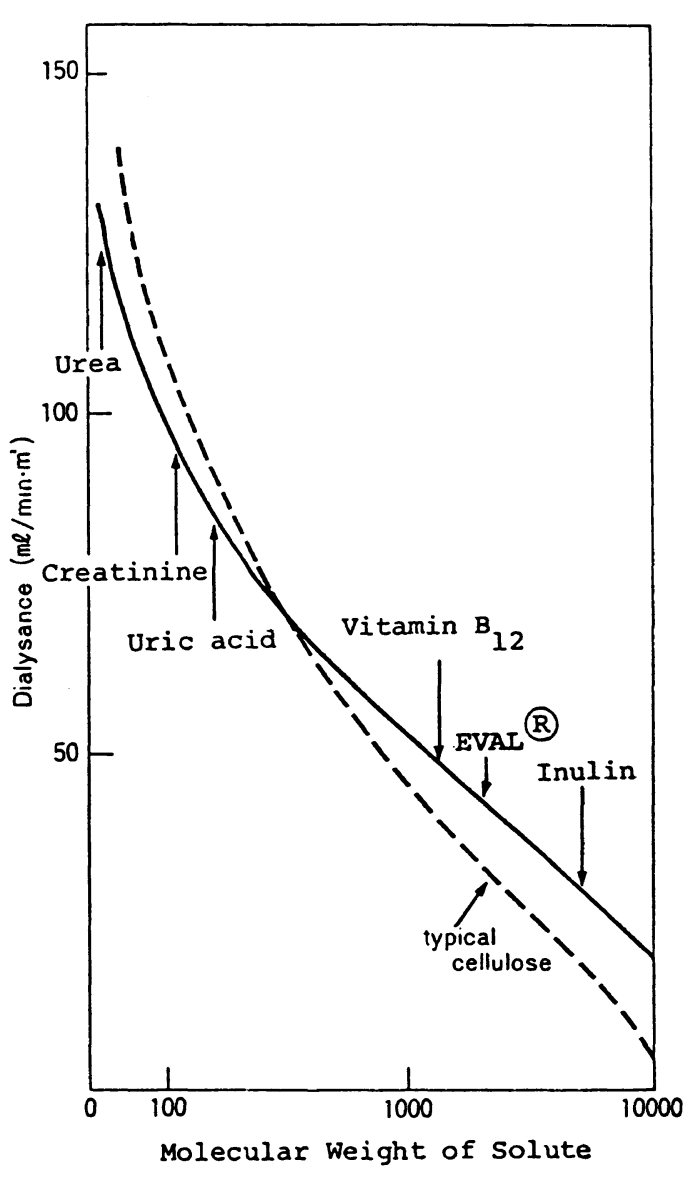

Figure 10. Permeabilities for solutes of EVAL dialyzer KF-101 (Dialysance spectrum) in vitro. $Q_{\mathrm{B}}=200 \mathrm{ml}$ $\min ^{-1} ; Q_{\mathrm{D}}=500 \mathrm{ml} \mathrm{min}^{-1}$

EVAL membrane is used, however, it is possible to perform hemodialysis with less incidence of such symptoms. The disequilibrium syndrome is attributable to the rapid removal of low molecules such as blood urea. The fact that the EVAL membrane provides a mild dialysis by suppressing the removal of low molecules agrees with the clinical efficacy. In addition, in hemodialysis treatments with the EVAL membrane, there are much less incidence of anemia, pruritus, metastatic calcification and bone ache which are frequently experienced by chronic hemodialysis patients who use the cellulosic membrane: ${ }^{8}$ Such symptoms have been considered to be attributable to middle molecules with a molecular weight of more than 10000 including polypeptide. The fact that the EVAL membrane has good permeability for substances in the middle and high molecular weight ranges correlates well with the clinical efficacy.

Recently, a high incidence of carpal tunnel syndrome has been pointed out as one of the serious problems caused by the long-term dialysis treatment. This syndrome has been considered to be attributable to the accumulation of $\beta_{2}$-microglobulin, a protein with a molecular weight of 12000 , in the carpal tunnel. ${ }^{9}$ Because of its larger pore size compared with the cellulosic membrane, the EVAL membrane has higher permeability for $\beta_{2}$-microglobulin and EVAL hemodialyzer is expected to show clinical improvement to the complication of long-term dialysis.

Blood Compatibility of EVAL Membrane. Since the hemodialyzer is repeatedly used for patients with renal insufficiency for a long period of time, it is important to reduce the influence over the body as little as possible. In this sense, the blood compatibility of the membrane to be used is an important factor.

In hemodialysis, heparin is generally used as anticoagulant. However, the use of heparin is improper for patients immediately after surgery or those with bleeding risk factors and it has been pointed out that there are some side effects on the bone metabolism and lipometabolism caused by long-term usage of heparin. Because of its good blood compatibility, the EVAL membrane allows us to conduct hemodialysis successfully with less than half the amount of heparin required for hemodialysis using the conventional cellulosic membrane. If the EVAL hemodialyzer is performed under carefully selected conditions, even completely heparin-free hemodialysis can be conducted (non-anticoagulant hemodialysis). ${ }^{10}$ Although there are many dialyzing membranes of different materials available at present, only the EVAL membrane can achieve completely non-anticoagulant hemo- 

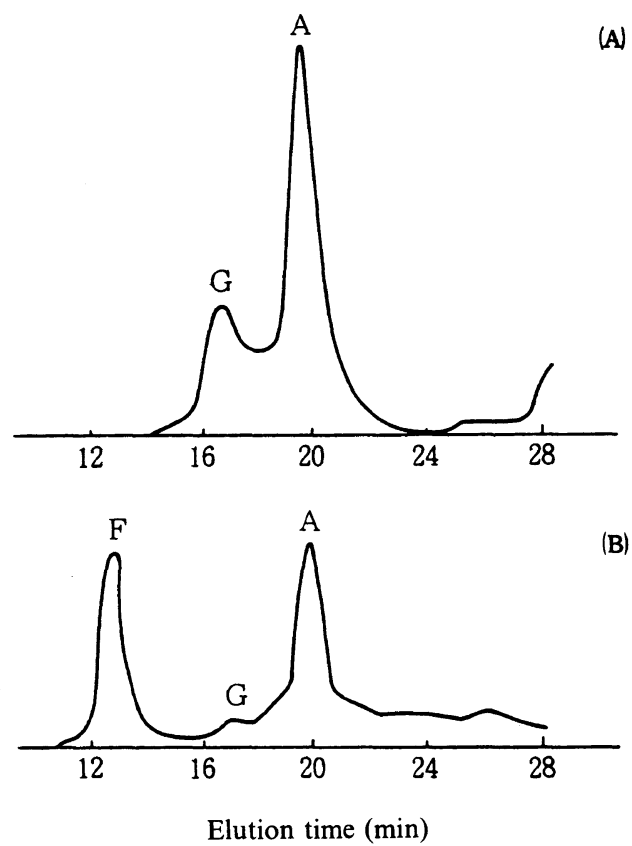

Figure 11. GPC of deposits on hollow fiber membrane. $^{12}$ (A) EVAL HFAK (non-anticoagulant hemodialysis); (B) Cellulosic HFAK (heparinized hemodialysis). A, albumin; G, globulin; F, fibrinogen.

dialysis.

The influence of various dialyzing membranes on the blood coagulation system has been investigated by many researchers and it has been demonstrated from ex vivo test that the EVAL membrane less activates such blood coagulation factors as contact activation factor (Factor XII), platelet factor 4 , and $\beta$ thromboglobulin than the cellulosic membrane or other synthetic polymer membranes. ${ }^{11}$ It is assumed that the good blood compatibility of the EVAL membrane is associated with the molecular structure, in which hydrophilic and hydrophobic groups are randomly bound, and with the unique heterogeneous microstructure on the membrane surface. By investigating the amount and kind of proteins deposited on the surface of membranes after the contact with blood, it has been made clear that, as shown in Figure 11, the cellulosic membrane has a thick layer of vari- ous proteins including fibrinogen on its surface while the EVAL membrane has thin uniform deposition of albumin-rich proteins producing a non thrombogenic surface. ${ }^{12}$

There are many symptoms attributable to the contact of blood with the membrane material: as acute symptoms, anaphylactic shock, transient leukopenia, and pulmonary hypertension are known; as long term ones, immunodeficiency and amyloidosis are often observed. The correlation between the side effects due to the extracorporeal circulation and the complement activation due to the membrane is a subject of controversy and is to be clarified in the future. ${ }^{13}$

In this respect, however, it has been already reported that complement activation and transient leukopenia are less severe in the patients treated with the EVAL membrane than those with the cellulosic membrane. ${ }^{14}$

\section{Application to Plasmapheresis}

Plasmapheresis has begun to attract attention as a new blood purification technique. Dealing with all plasma components including large molecules with a molecular weight of several million, this technique is very effective for the treatment of diseases whose etiology is attributable to either proteins or substances bound to proteins. Up to now, plasmapheresis has clinically indicated effectiveness for intractable diseases such as rheumatoid arthritis, myasthenia gravis, and fulminant hepatitis. ${ }^{15}$ Actual procedure of plasmapheresis is as follows: the patient blood is withdrawn to form extracorporeal circulation and separated by the plasma separator into blood cell components and plasma components; the separated plasma is discarded and replaced with normal plasma (plasma exchange) or toxic substances are selectively removed from the separated plasma with the membrane or adsorbent and the toxic substance-free plasma is then returned to the patient along with blood cell components.

Characteristics of PVA Membrane Plasma 


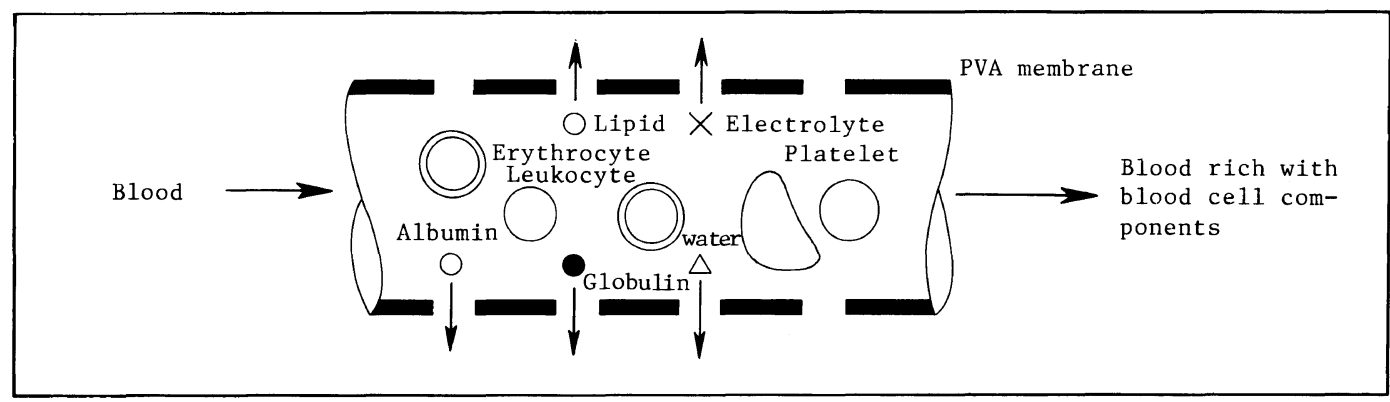

Figure 12. Principle of plasma separation by PVA hollow fiber membrane.

Separator. Until a few years ago, centrifugation was only device for plasma separation, using the difference of specific gravity of each component. However, because of expensive cost of equipment, complicated operational method and contamination of plasma by platelets, alternative method of plasma separation using various kinds of membranes of microporous structure has been subject to clinical acceptance. Figure 12 shows the principle of plasma separation with the PVA hollow fiber membrane. ${ }^{16}$

Membrane plasma separator is to meet the following requirements: (1) the plasma filtration speed is sufficiently high and stable during procedure; (2) blood cell components such as platelets are completely blocked while high molecular weight solutes such as proteins are highly permeable; (3) there occurs no hemolysis; (4) good blood compatibility is assured; and (5) the amount of eluate is small and safety is assured. To meet these requirements, besides the membrane material, the surface area of the membrane, pore size, distribution of pores, porosity, and module design should be considered as essential factors.

The PVA membrane plasma separator sufficiently meets the above requirements, and has been recognized as an excellent therapeutic plasma separator. As shown in Figure 13, the PVA membrane plasma separator allows complete permeation of all the proteins including IgM with a molecular weight of $950,000 .{ }^{17}$

The filtration rate $\left(J_{\mathrm{F}}\right)$ of plasma is closely

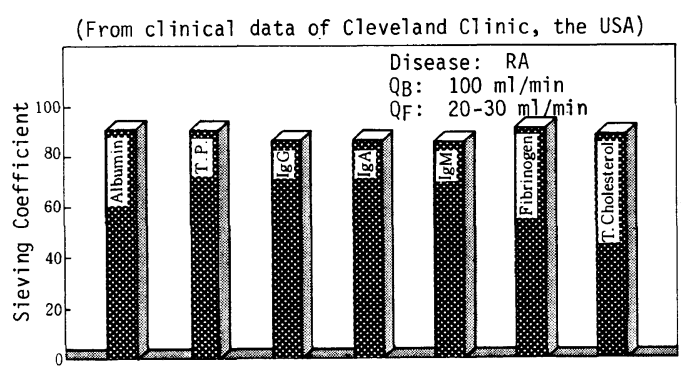

Figure 13. Sieving coefficients of PVA plasma separator for proteins. ${ }^{17}$

related with the wall shear rate $(\gamma)$. In case of the PVA membrane, the relationship is expressed by: $J_{\mathrm{F}}=1.95 \times 10^{-6} \gamma^{0.78}$. With the optimum selection of the membrane and module design, the PVA membrane plasma separator is provided with a higher filtration rate than plasma separators with other types of membrane. ${ }^{18}$ Plasma separators which are available in the market often show the lowering of the plasma filtration rate with time. This is attributable to the adsorption of proteins on the surface of the membrane. The hydrophilic PVA hollow fiber membrane clearly adsorbs less amount of proteins than the hydrophobic membrane such as polypropylene and thus provides stable filtration for a prolonged time. ${ }^{19}$

In recent years, the blood compatibility such as complement activation has been investigated on plasma separation membranes. ${ }^{20,21}$ The PVA membrane activates the alternative pathway of the complement system and pro- 


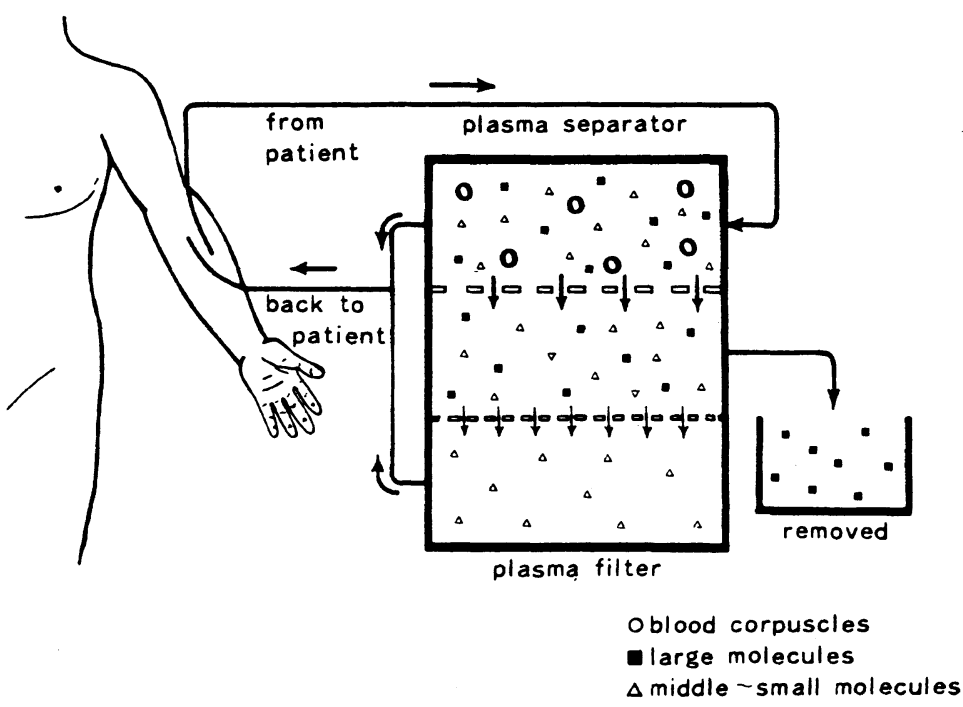

Figure 14. Principle of DFPP. ${ }^{23}$

motes the production of fragment $\mathrm{C} 3 \mathrm{a}$, but causes almost no elevation of the C5a level. $\mathrm{C} 5 \mathrm{a}$ is considered to be associated with anaphylactic symptoms as an anaphylatoxin and promotes the production of Interleukin I, an intrinsic pyrogen. On the other hand, C3a brings about the promotion of phagocytosis. Therefore, the PVA membrane, which activates C3a chiefly, seems to be rather effective, especially for the treatment of autoimmune diseases. ${ }^{22}$ Moreover, the PVA membrane less promotes the production of Interleukin I than other plasma separation membranes such as polyethylene and poly(methyl methacrylate) (PMMA).

Double Filtration Plasmapheresis (DFPP). Plasma exchange, one of the blood purification techniques widely conducted thus far, requires large amounts of expensive replacement plasma and occasionally causes some side effects such as hepatitis and alergy from those replacement plasma. Double filtration plasmapheresis has been developed to solve these problems (Figure 14). ${ }^{23}$

This technique is as follows: the blood withdrawn from the patient is first separated by the plasma separator (primary filter) into the blood cell components and plasma; the separated plasma is then led to the plasma fractionator (secondary filter) which has a smaller pore size than the primary filter, and is subject to separation into two portions of large molecules (including toxic substances) and useful small molecules such as albumin; and the former is discarded while the latter is returned to the patient along with the blood cell components. DFPP offers much saving of replacement plasma over plasma exchange, and yet brings about a clinical effect comparable to that of plasma exchange. ${ }^{24}$

The DFPP system which we have developed, consists of the PVA plasma separation membrane as primary filter, and EVAL hollow fiber membrane as secondary filter. There are three types of EVAL hollow fiber membranes (2A, $3 \mathrm{~A}$, and $4 \mathrm{~A}$ ) with different pore sizes available for different purposes of the treatment. Figure 15 shows the sieving coefficients of each EVAL membrane for solutes. ${ }^{25}$ Membrane having greater pore size $(4 \mathrm{~A}>3 \mathrm{~A} \cdot>2 \mathrm{~A})$, gives higher sieving coefficient for each solute. The sieving coefficient lowers in proportion to the molecular weight of the solute. For the separation of albumin and IgM, EVAL-4A membrane is 


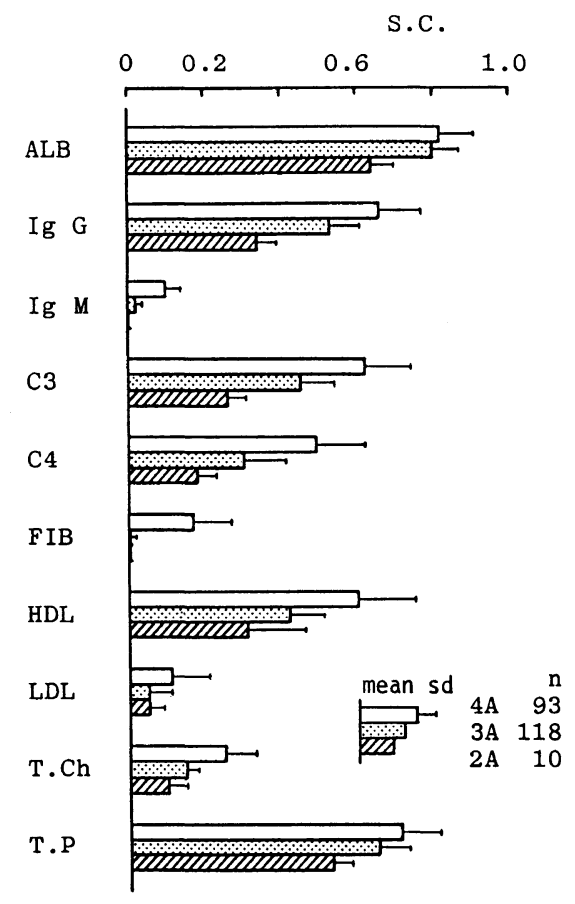

Figure 15. Sieving coefficients of EVAL plasma fractionator for proteins.

suitable. On the other hand, EVAL-2A membrane is used for separating albumin and IgG.

As shown in Figure 16, the permeabilities and separation characteristics for solutes are more stable in the EVAL membrane than in the cellulose acetate membrane regardless of the transmembrane pressure. ${ }^{26}$

By controlling the pore sizes of PVA and EVAL membranes more severely and by combining them properly, it becomes possible to fractionate more selectively the plasma components by molecular size. In this way DFPP is expected to gain wider acceptance in the future as a more complete therapeutic method.

\section{CONCLUSION}

In addition to the above-mentioned blood purification techniques, the application of the membranes derived from PVA and EVAL has been advanced into such fields as the ascites treatment and hemoconcentration. ${ }^{27}$

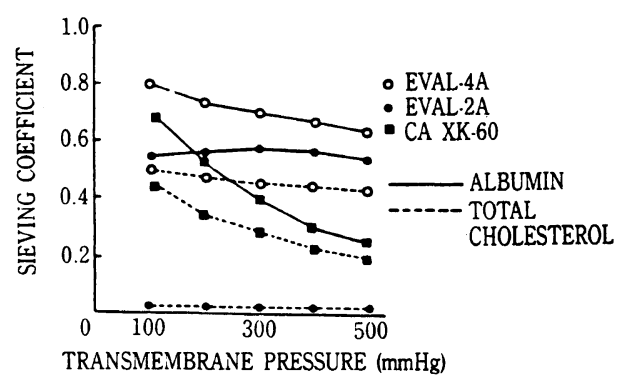

Figure 16. Comparison of permeabilities between EVAL hollow fiber and cellulosic acetate hollow fiber (CA) as plasma fractionating membrane (in vitro test with bovine plasma).

In recent years, research and development of biomedical materials have been accelerated, reflecting the diversified needs in the medical field, and therefore it is necessary to use the material with appropriate characteristics in accordance with the purpose. In the research and development of the PVA, Japan has taken the lead from the beginning and has accumulated extensive basic data thus far. Moreover, utilizing the reactivity of the PVA polymer, the research of various kinds of PVA derivatives with special functions is now under way. ${ }^{28}$

New researches being conducted on the basis of the previous technology and data, can offer more possibility of developing new materials derived from PVA and its copolymers for medical applications. They will surely be making an important contribution to medical science.

Acknowledgment. This paper is the fruit of the efforts by many people concerned in the research and development of PVA and EVAL hollow fiber membranes. Those achievements described in this paper were only possible by the strong cooperation between many medical doctors who have tested and used our materials and many colleagues of KURARAY. Authors of this paper are merely representing those people. We are pleased to acknowledge the considerable assistance of those people. Especially we wish to thank Dr. Y. Nose, Dr. 
P. S. Malchesky, Dr. T. Agishi, Dr. H. Naito, Dr. A. Saito, and, Dr. K. Takakura who have generously contributed information and suggestions for the preparation of this paper.

\section{REFERENCES}

1. I. Sakurada, "Polyvinyl Alcohol Fibers," Marcel Dekker, Inc., New York, 1985.

2. H. Lee and K. Neville, in "Handbook of biomedical plastics," Pasadena Tech. Press, Calf., 1971, Chapter 15, p 21.

3. Y. Yamauchi, K. Takakura, S. Kawai, and A. Ohmori, Jpn. Patent No. 1032595 (1981).

4. A. Sueoka, P. S. Malchesky, and Y. Nose, Sep. Sci. Technol., 18, 571 (1983).

5. S. Kawai, K. Yamauchi, T. Tanaka, and H. Tanii, Proceedings of Seitai-Kogaku-Symposium (Japan), 1979, p 105.

6. A. Sueoka, Jpn. J. Artif. Organs, 15(1), 145 (1986).

7. K. Takakura and T. Nakashima, "Biomedical Polymer," Y. Imanishi, Takakura, and H. Tanzawa, Ed., Kagaku-Dojin, Tokyo, 1980, p 141.

8. A. Saito, H. Ogawa, T. Takagi, and T. G. Chung, Jpn. J. Artif. Organs, 13(2), 643 (1984).

9. F. Gejyo, T. Yamada, S. Odani, Biophys. Res. Commun., 129, 701 (1985).

10. H. Naito, Artif. Organs, 5 (suppl. 1), 670 (1981).

11. H. Naito, Jpn. J. Artif. Organs, 16, (1987), in press.

12. H. Naito, T. Miyazaki, A. Kubotsu, S. Takashima, K. Takakura, and M. Kawahashi, Jpn. J. Artif. Organs, 14(1), 45 (1985).

13. D. E. Chenoweth, "Hypersensitivity in Hemodialysis," R. L. Wathen, E. Klein, and Y. Nose, Ed., ISAO Press, Cleveland, 1984, p 11.

14. R. Imai, S. Matsuhashi, S. Kusakari, M. Nambu, and T. Sakai, Kidney and dialysis (Japan), 14(3), 297 (1983).

15. Y. Shiokawa, Saishin-Igaku, 39(5), 873 (1984).

16. A. Sueoka, P. S. Malchesky, J. Wojeicki, and Y. Nose, "Plasmapheresis," Y. Nose, P. S. Malchesky,
J. W. Smith, and R. S. Krakauer, Ed., Raven Press, New York, 1983, p 149.

17. Y. Abe, C. Katsume, E. Blasutig, M. Ueno, T. Matsugane, J. W. Smith, P. S. Malchesky, and Y. Nose, "Cryofiltration using polyvinyl alcohol membrane filters" in "Plasmapheresis," Y. Nose, P. S. Malchesky, and J. W. Smith, Ed., ISAO Press, Cleveland, 1983, p 295.

18. A. Sueoka, T. Inuyama, Y. Namba, and $\mathrm{K}$. Takakura, Jpn. J. Artif. Organs, 14(1), 318 (1985).

19. D. Randerson and J. Taylor, "Protein adsorption and flux decay," in "Plasmapheresis," Y. Nose, P. S. Malchesky, and J. W. Smith, Ed., ISAO Press, Cleveland, 1983, p 69.

20. T. Takaoka, J. B. Goldcamp, Y. Abe, T. Matsugane, E. Blasutig, J. W. Smith, P. S. Malchesky, and Y. Nose, Am. Soc. Artif. Intern. Organs, 30, 347 (1984).

21. S. Omokawa, P. S. Malchesky, H. Sakamoto, A. Flynn, M. A. Loftus, and Y. Nose. Trans. Am. Soc. Artif. Intern. Organs, 32, (1986), in press.

22. S. Murabayashi, S. Omokawa, T. Takaoka, P. S. Malchesky, and Y. Nose, Abstract of the 1st International Congress of the World Apheresis Association (May 20-23, Tokyo), 1986, p 43.

23. T. Agishi, I. Kaneko, Y. Hasuo, Y. Hayasaka, T. Sanaka, K. Ota, H. Amemiya, N. Sugino, N. Abe, T. Ono, S. Kawai, and T. Yamane, Trans. Am. Soc. Artif. Intern. Organs, 26, 406 (1980).

24. T. Agishi, H. Amemiya, K. Ota, and N. Sugino, "Plasmapheresis," Y. Nose, P. S. Malchesky, and J. W. Smith, Ed., ISAO Press, Cleveland, 1983, p 127.

25. T. Miyahara, A. Sueoka, T. Suzuki, Y. Ueda, N. Yamada, Y. Ikeda, and Y. Yagiri, Jpn. J. Artif. Organs, 15(3), 1566 (1986).

26. A. Sueoka, T. Miyahara, S. Takashima, K. Takakura, K. Kubotsu, T. Yamane, M. Kawahashi, Jpn. J. Artif. Organs, 13(2), 931 (1984).

27. K. Matsuzaki, S. Kitagawa, Y. Nonami, M. Yamasaki, S. Izumi, T. Yamashiro, I. Tamiya, A. Sueoka, and S. Horibata, Jpn. J. Artif. Organs, 15(2), 1052 (1986).

28. J. Yamauchi, Seiyaku-Kojo, 4, 547 (1984). 